\title{
9
}

\section{LIVING WITH MOSQUITOES IN DISEASE-FREE CONTEXTS}

\section{Attitudes and perceptions of risk in English wetlands}

\author{
Adriana Ford, Mary Gearey and Tim G. Acott
}

Mosquitoes are amongst a small coterie of insects whose mention within general conversation provokes an instant reaction. Joining ticks, horseflies and midges, mosquitoes conjure in the mind a time, a place, of interaction. Human and mosquito lives are entwined. Most people can recollect mosquito encountersof high-pitched whines that prevent sleep, of walking through swarms on a summer's evening, of inflamed bites scratched until they bleed. Mosquitoes are intrinsic to what cultural cartographer Rebecca Solnit (2010) describes as the "living maps" of our perambulations through our lives and through places; an unbidden fellow traveller whose companionship we never quite manage to shake off, and whose presence appears at the most intimate of times.

Humans and wetlands have been interconnected across time, deep time. Though deep time is a contentious term (Irvine 2014), we can say that over the millennia, humanity's dependence on wetlands for all aspects of survival is noncontestable (Schmidt 2017). This is true even now, as wetlands across the globe provide a range of ecosystem services which humans depend on, including food provisioning in forms as diverse as agro-industrial rice production, cranberry harvesting, subsistence fishing, foraging and wildfowling. Human development is closely linked with wetland environments, and this in turn has meant that humans have sought to live alongside fellow wetland species-including mosquitoes.

This interspecies co-mingling as espoused by Haraway (2007) has not necessarily prompted empathy with other forms of being. The progression towards settled farming practices, from the Neolithic onwards, resculpted landscapes anthropomorphically. Cleared forests, for example, have become over time the sites of our present-day peatlands (Gearey et al. 2000). This is evident more clearly in the ways in which wetland ecosystems have been adapted by humans over time, particularly in the Global North, where draining wetlands to extend agricultural land becomes, over time, closely tied with nation-building and forms 
of political economy (Gearey et al. 2020) and, by extension, colonialist projects of empire building (Howell 2018). This encroachment of human activity upon and within wetlands disrupted and altered human-mosquito relationships. Social historians (Watts 2006, Cohen 1983) cite the development of drainage channels as part of wetland co-option into agricultural artefacts as the driver of increased incidences of malaria. These drainage channels provide emergent breeding grounds for mosquitoes. More intensive forms of agriculture bring humans and mosquitoes into closer proximity to enable vector transmission of the disease.

Malaria, once known as ague, was endemic in Britain from the fifteenth century and was often associated with wetland areas as "marsh fevers," attributed to "the noxious vapours of stagnant marshes" (Dobson 1989: 3). In the first half of the twentieth century, prominent scientists at the British Mosquito Control Institute on Hayling Island, just off the south coast of England in Hampshire, facilitated research and shaped public consciousness around the "gravity of the menace" of the British mosquito (Hogarth 1928, Coates, this volume). However, with indigenous malaria eradicated in the UK in the mid-twentieth century, local British attention to mosquitoes declined. Yet in the twenty-first century, with increasing global temperatures facilitating the spread of mosquitoes and mosquito-borne diseases in other parts of Europe (Semenza and Suk 2018), combined with tabloid headlines designed to provoke fear and panic - "Horror as plague of killer mosquitos are headed to Britain as fears ramp up over insects"-mosquitoes, and their breeding grounds, may once again be viewed with anxiety (Hudson 2019, also see Swain 2012, Daily Mail 2019). Mosquitoes in Britain, of which there are 36 recorded native species, are monitored by public health authorities such as Public Health England (e.g. Vaux and Medlock 2015, Public Health England 2017) and local district councils (see Dover District Council 2020). Most of the native species in Britain do not transmit diseases, but some species have transmission capability (e.g. West Nile virus by Culex mosquitoes, and dengue and chikungunya by the invasive species Aedes albopictus). However, little is known about the perceptions towards mosquitoes in countries such as the UK, where mosquito-borne diseases are only a possible risk and not yet (or no longer) a reality. Are mosquitoes on people's consciousness as a native pest and cause for concern, or do people live in relative harmony alongside them? Might perceptions towards mosquitoes affect wetland management, restoration and creation, or are they inconsequential when viewed alongside the multiple values, or perhaps other risks or challenges, associated with wetlands?

Within a broader exploration of the values of English wetlands and the management of mosquitoes in the interdisciplinary WetlandLIFE project, an initiative of the Valuing Nature Programme of the UK Research Councils, we relied upon the Community Voice Method (CVM) for filming interviews and making documentaries (Ranger et al. 2016), focusing especially on human experiences and perceptions of mosquitoes. Fifty-six wetland users at three sites of different English wetland typologies (Somerset Levels, Bedford urban wetland parks and the Alkborough Flats), provided a snapshot into experiences and perceptions of these notorious insects in a very local context [see Box 9.1 and Figure 9.1]. 


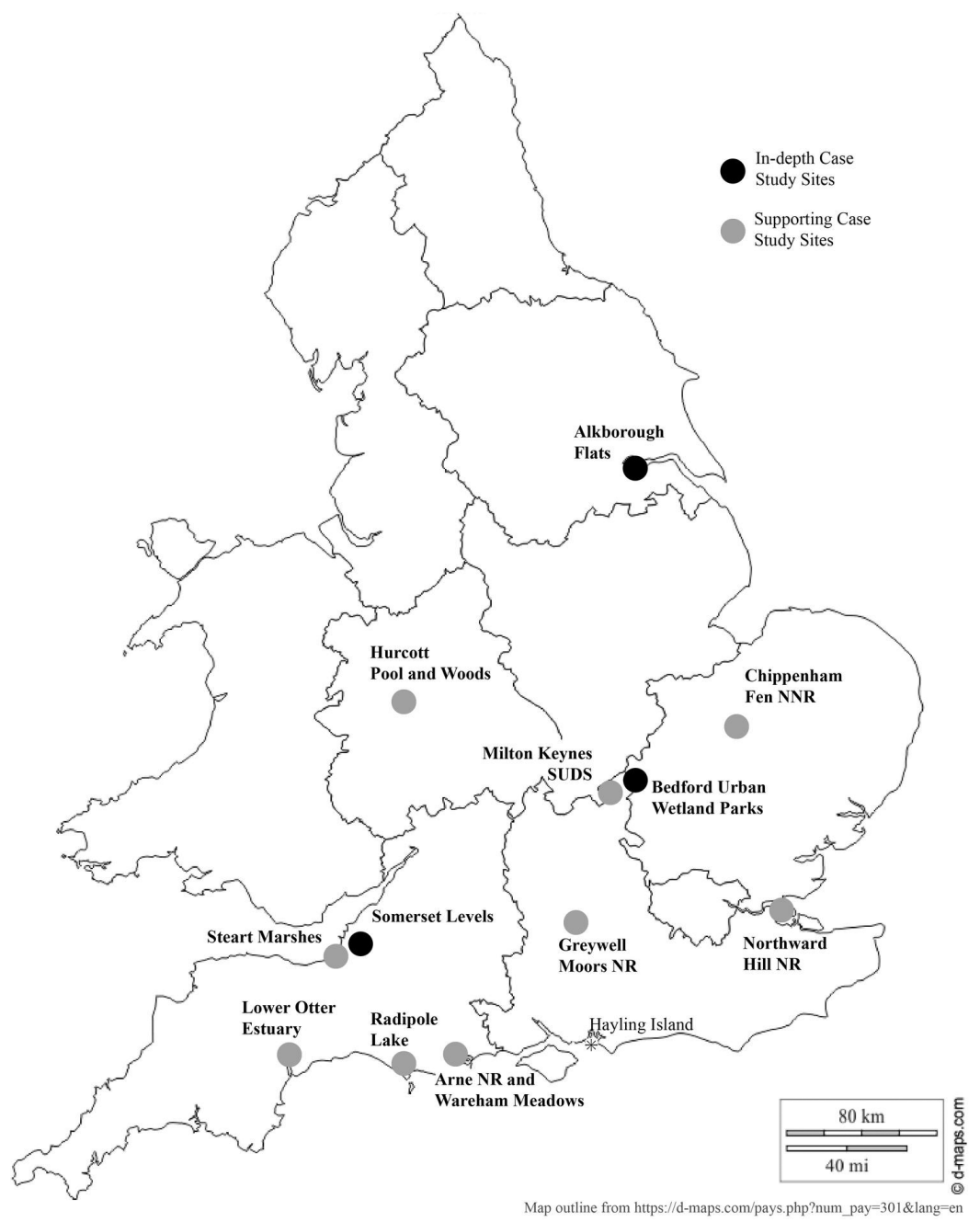

FIGURE 9.1 WetlandLIFE case study sites. Courtesy of WetlandLIFE, UK.

The interviews of farmers, reserve managers, volunteers, walkers, birdwatchers, and other recreational wetland users and local residents, conducted throughout 2018, were designed to capture people's relationships with their local wetland environments, to interrogate the ways in which their sense of place and attendant health and well-being practices are produced and articulated within these spaces, and to suggest implications these have for wetland management. In this chapter, we present our findings from the mosquito-related dialogue, a deliberate line of exploration, which helps us to understand how people experience living with mosquitoes in disease-free contexts such as the UK. Some of these views are also captured in a short film, Mosquito $\&$ Me - a narrative on mosquitoes in English wetlands in 2018 (Ford, 2019b). 


\section{BOX 9.1 ENGLISH WETLAND CASE STUDY SITES}

Three case study sites in England were chosen for in-depth research in the WetlandLIFE project, each representing one of three drivers for wetland expansion identified in the "Wetland Vision for England" (Hulme 2008) - farmland reversion, coastal realignment and urban wetlands. The ecological research in WetlandLIFE also included a further nine study sites; over the course of the project across the 12 sites, more than 39,000 adult mosquitoes, representing 19 British species, were collected and identified (Hawkes et al. in prep).

The Somerset Levels (South West England) was chosen as an example of farmland reversion wetlands, as former peat-harvesting sites. The study site consisted of two separate but neighbouring wetland nature reserves, Shapwick Heath and Westhay Moor, which form part of an assembly of wetlands known collectively as the Avalon Marshes. For the Community Voice research, the broader landscape (the "moors" or "the Levels"), which are prone to flooding, were also included. In the WetlandLIFE ecological study, traps in this study site yielded the second-highest mosquito abundance (over 9,000 adult mosquitoes). This included nine species, the majority (81\%) were Aedes cantans/Aedes annulipes, which are not considered disease vectors, but can be serious nuisance-biters for mammals, including humans and livestock (Hawkes et al. in prep).

Alkborough Flats, in a rural part of North Lincolnshire (North East England) on the southern side of the Humber Estuary, was chosen as a coastal wetland. It is the site of one of the largest managed realignment (MRA) schemes in Europe, which was aimed primarily at reducing flood risk further inland. The site, which prior to the MRA scheme was lowlying agricultural land, is now an established wetland nature reserve. "The Flats" are overlooked by the small village of Alkborough. In the ecological study, Alkborough Flats was the site of the single trap with the greatest number of mosquitoes (11,228 mosquitoes), $92 \%$ of which were the species Aedes caspius, which can be a severe nuisance-biter. Anopheles claviger, a recognized malaria vector (although not historically in Britain), was also present (Hawkes et al. in prep).

- Two country parks with wetland habitats, located close to Bedford town centre (East of England), were chosen as the location of urban wetland research. There are few natural lakes in Bedfordshire and both the study sites-Priory Country Park and Millennium Country Park-were created from the former sites of industrial extraction of gravel and clay. Both parks are managed for recreation, wildlife conservation, environmental education and community participation, as well as cultural and heritage value, and have high visitation. In the ecological study, the Bedford sites had the greatest species richness, with 13 species present, but yielded moderate to low numbers of adult mosquitoes (Hawkes et al. in prep). 
This following section explores what Mick Smith (2013) has described as the relevance of post-humanist perspectives for uncovering the myriad ways that humans and the-more-than-human collaborate together. These often low-visibility "ecological communities" provide ways to counter dominant extinction narratives that view certain life forms as a pest and possibly a threat to human health. One can consider the ways in which scientific funding has been provided to try to eradicate those insects and animals seen as threats: termites, tsetse flies and tape worms amongst others. Yet removing these creatures entirely from the "web of life" (Moore 2015) may have untold long-term consequences for food chains and ecosystems. In other words "staying with the trouble," to reiterate Haraway (2016), enables us to recognize that other forms of "being together" may enable alternative sustainable futures. When we consider mosquitoes as potential disease vectors, understanding how they are currently valued and factored into wetland ecosystems may help us all manage change in the future. To understand mosquitoes as the "enemy" is to view ourselves within a framing in which nature is a battlefield and humans are the conquerors. Posthumanism, by contrast, seeks to recognize the fundamental connectivity of humans within nature, and that our animal selves have always been connected in relationships of kinship both with other animals and attendant environments. Malone (2019: 107) has described this connectivity as, "a recognition that we are animal, we are nature, and we carry the ghostly tracings of our shared past."

\section{Human-mosquito interactions: interrogating the lived experiences of interspecies co-mingling}

Whilst ecological surveillance provides information on the status, distribution and abundance of endemic mosquitoes, and identifies occurrences of invasive species (Public Health England 2017), an analysis of the "lived experience" of human-mosquito interactions, derived from the social sciences, provides insight into what the presence of mosquitoes means to people. The experiences, or encounters, people have with mosquitoes may influence their attitudes towards perceived risks, and so possibly towards the habitats with which they are associated, such as wetlands, and how these habitats should be used or managed. As a baseline for understanding how people are living with mosquitoes, one thus needs knowledge of people's experiences with mosquitoes. Do they see mosquitoes? Do they get bitten by them or experience other types of interactions with them? Have such interactions changed over time?

As anticipated when considering various wetland sites, we found the extent and frequency of human-mosquito interactions varied considerably across the sites, individuals and time. In many cases, human-mosquito interactions were not experienced at all in their local wetlands - mosquitoes were neither seen, nor felt-particularly at the urban sites in Bedford. Some respondents said they had never even thought about mosquitoes in the context of their local wetland site, until participating in this study (we made clear that the sites were not chosen because there is an exceptional mosquito problem!). Often though, mosquitoes 
were noticeably present, seen visibly (although people can mistake other insects for mosquitoes) - sometimes just one or two, sometimes in swarms, and usually in the summer months-and of course, sometimes the mosquitoes were felt. And it was not just the human-mosquito interactions that were relevant; farmers reported bothersome swarms, and biting, by mosquitoes, of their horses and livestock.

Perception of change may influence perception of future risk; thus, if mosquito presence appears to be increasing, that may create or add to fears for the future. We had no preconception about whether there may have been more, less or the same current density of mosquitoes compared to the past in our study sites, and most of our respondents could not identify or recollect any patterns or changes in mosquito presence and density over time. There were some exceptions though; for example an ornithologist in Bedford noted that "they've declined quite a lot; there were quite big swarms of them 20 years ago ... which they're not now; it's just the occasional one or two in comparison to what they used to be" (Int. B10), and in Somerset a farmer noted: "I think we are so close to open water and over the years, the 20 years that we've been here, living as a couple here with our family, I would say that it has progressively, year on year, got worse" (Int. S2). Some participants of the Alkborough site emphasized that they had not seen a "before and after" change in mosquitoes since the creation of the wetlands, although one farmer perceived there to be more of them, and more vicious:

There are more. There are more. And I don't know whether it's just because there are more, but they seem to be hungrier. If you're down there on the wrong sort of day, it's bad, and also the cows suffer far more with flies than they did in the past. But it's not an insurmountable problem.

(Int. A8)

These apparently inconsistent claims about mosquito numbers may seem perplexing. One explanation is that mosquitoes can be misidentified, giving rise to a perception of change that is not actually occurring. Another possibility is that even at the same study site, there are diverse habitats and ways of interacting with the wetlands that vary by location, time of day or duration. The heterogeneity of mosquito habitats, and therefore their populations, can create very localized experiences. Another explanation may lie in the context within which insects, and particularly mosquitoes, are viewed in individual cultural contexts. Attitudes and perceptions of risk are both culturally coded and heuristically shaped. The ways in which we frame our "sense of place" is a two-way dynamic between our lived experiences and the wider "metanarratives" of the contemporary social representations we are embedded within, and then communicated through various forms of epistemological knowledge dissemination, whether pedagogical, scientific, legal, medical or cultural. Articulations of mosquito encounters, and perceptions of risk, then 
become something much more; they become articulations of a sense of place, and of the actors' own understanding of their contribution to world-making. As we explore in the sections below, understanding these often contrary articulations of perceptions of mosquitoes within English wetlands may be less about differences in species and habitat across the wetland sites, and more about which actors share sensibilities around their own senses of place within natural settings.

To explore sensitivities to place and to the mosquitoes that inhabit them, the next section reports on the ways in which study participants articulated their experiences with mosquitoes. Even if some of the participants did not encounter mosquitoes in their local wetlands, one can learn from those who do, allowing us to identify three types of impacts associated with mosquitoes: health impacts, the nuisance factor and behavioural adaptions.

\section{Health impacts}

As mosquitoes in the UK no longer transmit diseases to people, their effects on human health is virtually absent when compared to countries that are rife with mosquito-borne diseases. The only negative effects of mosquitoes in the UK stem from their bites. Many of our participants had observed that some individuals are more susceptible, and react more severely, to a mosquito bite, even if most agreed that a mosquito bite was a trifling occurrence. There were some exceptions to this generalization, the most notable being in Somerset, where a couple with children on a small farm located near a wetland environment complained about vicious mosquitoes. There, mosquitoes have led to skin reactions in one child who required medical treatment:

One of them, from a very young age, whenever she was bitten, she has eczema as well, and it just would exacerbate her eczema, and then she would end up with very bad skin infections which most summers would result in two or three courses of antibiotics. We're just finding now that her skin problems are still continuing, even though she's at an age when really she should be growing out of it, so that's requiring some more significant treatment now.

(Int. S2)

Another farmer at Somerset reiterated the severe reaction one might get from a mosquito bite: "my whole hand swelled up didn't it, for about three or four days. I couldn't do anything with it" (Int. S17). In the Alkborough site, one participant living just above the Flats shared an even more serious story of biting mosquitoes, albeit from 20 years ago:

There's been rare mosquitos, when I lived in [the neighbouring village] Walcot we all got bit one year and we had terrible reactions that sort of hospitalized 
a lot of my friends. It was my 18th party, and they all got bit and they swelled up really, really badly. Some had to go to A\&E, some just went to the doctor's and got a prescription. Okay it was 20 years ago, but there was a really ... they said there was a really bad batch so to speak that people had reacted.

Whilst other parts of Europe have seen a number of incidences of mosquitoborne diseases that adversely affect human health (Semenza and Suk 2018), there has not been a reported case of a mosquito disease infection in the UK for decades. However, tick-borne Lyme disease is a recognized growing health concern, debilitating its human host in episodic cycles over many years, serving to diminish the concern over mosquitoes. The arthropodal enemy has apparently shifted. Mosquito bites in the UK, even severe reactions to them, pale in comparison with the threats carried by ticks, which lurk in grasses and attach to our skin with neither whine nor flight to alert us to their presence. Returning once again to Smith (2013), one must also consider the web of life's connectivity to the tick's survival, which like the mosquito, depends on the blood of a host mammal or bird to provide the sustenance for its reproductive cycle. This connects us again to the ecological community in which humans are enmeshed with other species. A mosquito may be less enemy than co-respondent; to live alongside one another may be to accept how each affects the other's well-being.

\section{The nuisance factor}

Although mosquitoes may be perceived as an irritant in the UK rather than something to be immediately feared, they are still considered a nuisance by many of the respondents, and perhaps a blight to long English summers. Negative human-mosquito interactions are easy to recall particularly by marring the "rural idyll." Here, human contentment rests with a natural setting, prompting an idea of a wholesomeness and sense of well-being that can only be gained in nature-even if this is illusory. Mosquitoes, along with such sensory irritants as smelly slurry pits and obstructive electricity pylons, disrupt our imaginative framing of what the countryside should look like and what we, as humans, should experience. All of the disruptors can be classed as "nuisance factors."

Even so, many participants reported that mosquitoes are not something they have thought much about in a UK or local context. They gauge local mosquitoes in comparison with other places where they have perceived a far worse experience, particularly Scotland's west coast or tropical countries. Another internal gauge is their comparison of mosquitoes with more problematic creatures-particularly midges, and horseflies-who may combine forces to disrupt a paradisiacal weekend retreat. One respondent volunteered that:

Our worst experience of, I don't know about mosquitoes, is the West Coast of Scotland, isn't it? The midges and stuff like that, and there are a few 
months in the year where I feel that we shouldn't visit our relatives because you just get bitten to death, in fact you can come home and you're sort of red. In Lincolnshire, the worst thing is you're in a wooded area, you get horse flies and stuff don't you?

(Int A1)

Another participant noted more graphically that in Scotland, "the mosquitoes come attached with chainsaws" (Int. S11) (Figure 9.2 and 9.3).

The irritation and annoyance effected by mosquitoes, though not universal amongst respondents, commonly elicited such terms such as "hate" and "death." Yet, as will be discussed further, these negative reactions place mosquitoes as free agents who loom large in the imagination as foraging biters. The role of humans in creating mosquito-friendly habitats was rarely mentioned in conversations: nature as salve and nature as irritant reveals our complex positionality with our other-than-human brethren. Wickson (2010) sums up a positivist approach to human relationships with nature, declaring "Mosquitoes: just how much biodiversity does humanity need?" Whilst humans may remain centre stage as administrators of life on the planet, there is less likely to be simple acceptance of

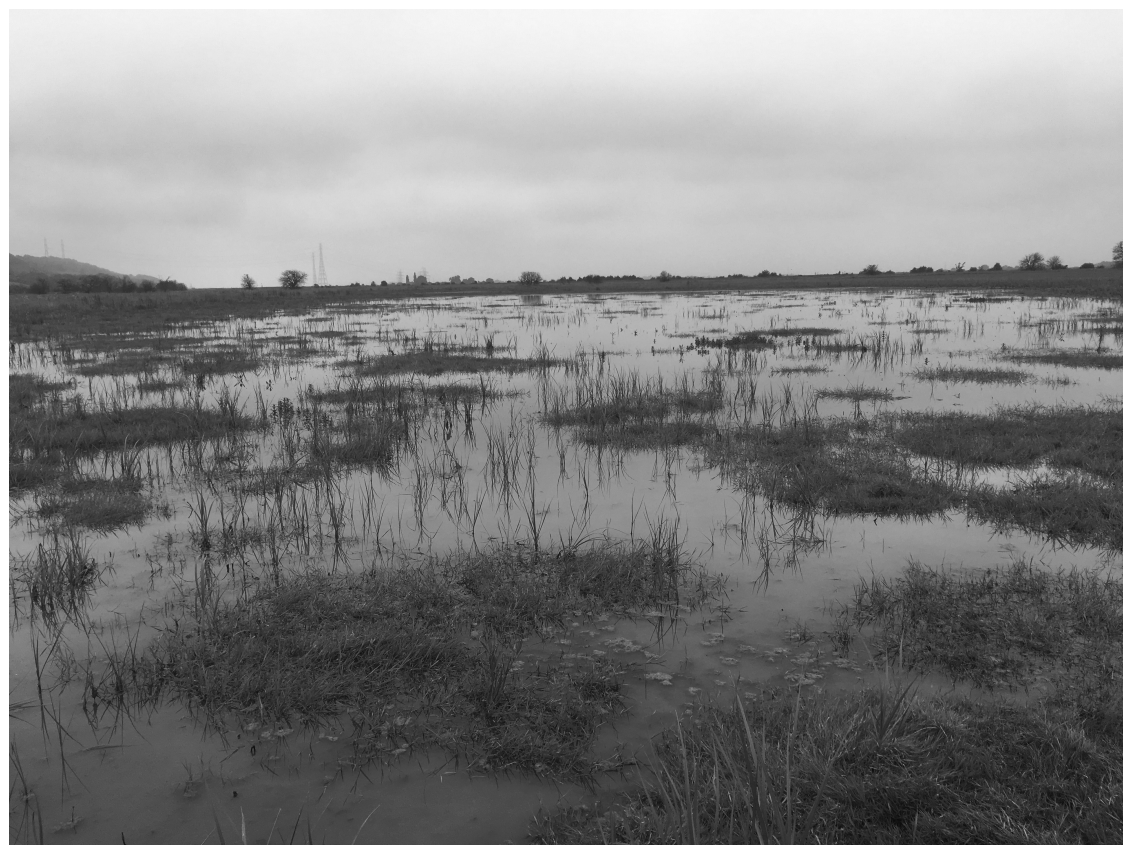

FIGURE 9.2 Estuarine flooded habitat for the Aedes caspius mosquito (an aggressive human biter) at Alkborough Flats, a managed realignment site in North Lincolnshire, UK. Photography by Frances Hawkes/ NRI. 


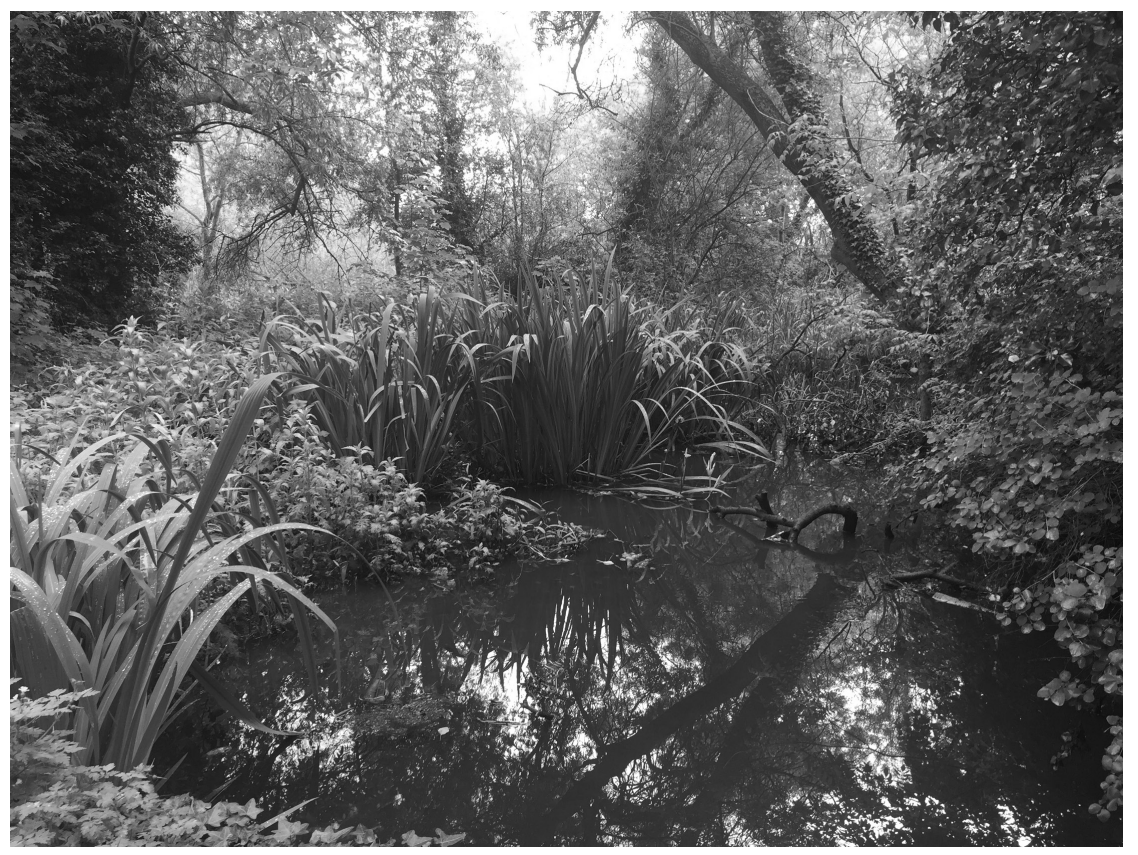

FIGURE 9.3 A wetland environment and mosquito habitat in the urban Bedford study site in East of England, UK; 13 species of mosquito were found in WetlandLIFE adult mosquito traps in Bedford. Photography by Frances Hawkes/ NRI.

mosquito-human interactions and instead there may be a move to enact change, especially change which favours human benevolence.

\section{Behavioural adaptations}

Where mosquitoes are present and a nuisance, there are three main approaches to dealing with them: ignoring them; managing their habitat and directly controlling them; or adapting one's behaviour accordingly. The last two methods, of course, are not mutually exclusive, but from the individual's perspective, behavioural adaptations are more controllable than influencing a mosquito management plan. Adaptations are dependent on the need and based on the extent or expectation of the problem, along with the ability and willingness to change. Many of our participants did not experience any mosquito interactions at all, and so required no adaptations; but for those who did notice mosquitoes, they reported taking many of the typical precautions. This included wearing appropriate clothing (e.g. long sleeves or not using yellow), avoiding certain places at certain times of day, using repellents and fires, consuming brewer's yeast (for purportedly altering the taste of blood), and even, closing one's mouth to avoid accidentally ingesting them! One extreme adaptation, given its 
association with more tropical environments, was draping bed nets, which was taken up by the family in Somerset referred to earlier:

Two of my younger sisters, they [the mosquitoes] just seem to really like them; they have to sleep under mosquito nets because it's that bad some of the time, there is a lot of them down here.

(Int. S2)

People's willingness and ability to adapt their behaviours are a vital part of learning to live with mosquitoes, and in so doing, minimizing the loss of value from the wetland environment- either by not enjoying it, or not being able to carry out such typical activities as bird-watching, strolling, farming, etc.

For our participants whose work or leisure time involved long motionless periods in the wetlands, including bat surveyors, ornithologists and wildlife photographers whose patience is repaid with an intimate knowledge of the flora and fauna or animal cosmologies, adapting to attendant mosquito environments is a pragmatic choice for using these spaces. Risk plays less of a role here than general comfort, and behavioural adaptations become a routine response to wetland conditions. These practices are sometimes multifunctional: insect repellent combined with sunscreen; longer sleeves to shield from sun and bug or the repellent actions of nettles and brambles; hats to prevent glare when peering through binoculars or camera lenses. The mosquitoes' inclusion in the matrix of wetlands means that preparations for visiting these areas become a ritual that adds to a person's sense of place: the insect repellent joins the thermos, the walking pole, the rucksack and the journal with pens. These moments of preparation attend to Shamai's (1991: 348) exploration of a sense of place as a processive collective that combines the recalled, the imagined and the actual: "A place is never merely an object, but part of a larger whole that is being felt through the "actual" experience of meaningful events." In this respect, the anticipation of a mosquito encounter is an accepted aspect of immersion into that space, even (or perhaps, especially) if the respondent finds it onerous or challenging. As Shamai explains,

the definition of a sense of place is: feelings, attitudes, and behaviour toward a place which varies from person to person, and from one scale to another (e.g. from home to country). Sense of place consists of knowledge, belonging, attachment, and commitment to a place or part of it.

(Shamai 1991: 354)

It is this "commitment" to a particular place that comes through clearly in our fieldwork. Our respondents' lives are embedded within these wetlands through their own volition. The attendant discomforts and "risks" of working within, living alongside, or utilizing these wetlands are connected with each person's own criteria for the negative and positive aspects of these sites, with mosquitoes occupying a shifting cost-benefit analysis as just one of many factors that must 
be contemplated. We realize then that human-mosquito interactions are embedded within wider personal ontologies of being-in-the-world; our perceptions are shaped both by expectation, constructed through cultural representations and social norms, and by experiencing phenomena which either support or run counter to these expectations. The Heideggerian encounter of "being-in-theworld" is simultaneously lived phenomena and part imagination and interpretation (Zahorik and Jenison 1998).

\section{Friend or foe? Perceptions of mosquitoes}

We have focused so far on the "lived experience" with the mosquito, the interactions people have with this insect and how they respond to these encounters. Yet, people's ability or willingness to live alongside mosquitoes also depends on their broader views, their interests and values, and their wider experience and understanding of mosquitoes in the world (Gearey et al. 2020). We must also recognize the importance of companionship or empathy that humans find with other animals, the "more-than-human", as an essential component of being human, and of making sense of the world. As Carol Smart suggests (2011: 36):

The field of human-animal interactions alerts us ... to be attentive to nonverbal communications and (to) forms of interaction not underscored by talk. It is a sensory world and as such is also part of everyday life.

Such sensorial experiences of a closeness with the animal world (see Ford 2019a) have been described in post-humanist philosophy as "the animal turn." Here, the hierarchy between humans and animals is flattened, focusing instead on interconnectivity and a web of life (Moore 2015) that depends on codependency. Specifically, we sought to reveal people's attitudes towards mosquitoes, linking them with broader experiences, and asking specifically whether they could be "friend" or always "foe."

\section{Friend}

Mosquitoes are normally dominated by negative connotations, as a nuisance and as killers. But from the perspective of many of the people we interviewed, "Could we or should we eliminate mosquitoes?" is a question that does not concern them since they simply do not experience mosquito interactions in their local wetlands. For those who do notice mosquitoes, they consider them mostly as nuisance rather than health threat. Of these mosquito-sensitive people, many have learned to live alongside the insects, adapting to them when using wetlands. Mosquitoes apparently occupy a fairly "neutral" role in the minds of many wetland users. Still, one wonders if mosquitoes can ever be viewed positively, as a "friend"? Our interviews revealed that, yes, the mosquito is indeed viewed positively, especially for the role that it plays in ecosystems. One conservationist 
with a deep passion for birds declared, "I love mosquitoes! I'll say it again, I love mosquitoes!" (Int. B8). His message was simple: mosquitoes are an insect, and insects provide food for birds; the more mosquitoes (and insects in general), the more birds. Insect populations, generally, have been in global decline, with some $40 \%$ of species threatened with extinction (Sánchez-Bayo and Wyckhuys 2019), and with the insect trend in the UK being no exception (Leather 2017). As the conservationist explained "I'm convinced that one of the biggest problems facing ... our bird life, certainly farmland birds and wetland birds, is the lack of insects" (Int B8). The importance and decline of insects were mentioned by several others, including a reserve manager:

I feel like even when I first moved here 30 years ago there were a lot more insects in the area and there were a lot more mozzies and midges, I think. I think we're losing invertebrates massively ... I see them as a food source for birds and amphibians, so a sort of source of life.

(Int S9)

Indeed, most participants across stakeholder groups acknowledged, or at least assumed, that mosquitoes play a role in the functioning of ecosystems, particularly as food for birds and bats. "It's an inconvenience but everything has its place," noted a farmer, "and maybe without the mosquitos we wouldn't have so many swallows. So it's swings and roundabouts" (Int. A8). "They're a fact of life and to be honest," said a conservation volunteer, "they are probably the biggest factor in the food chain; there are billions of them out there" (Int S11).

Another theme that emerged from the interviews was the rights of mosquitoes to exist as part of the ecosystem. "They're just part of the wildlife. They've got as much right to be here as anything else" (Int. B1). This is an ethical or moral argument that involves animal intimacies, and decentring humans as the central object of study. Anna Tsing's declamation, "human nature is an interspecies relationship," is the foundation of much of the WetlandLIFE project. Understanding and appreciating the close connectivity between humans, other animals and wetlands enabled us to appreciate how these multi-species spaces are the fabric of life on this planet. Many respondents considered mosquitoes integral to that fabric, part of the food web, or simply justifiable in their own right.

Nor are viewpoints static, inert parts of our consciousness; people constantly change their perceptions of things around them. In addition to the behavioural adaptations to mosquitoes mentioned above, there are perceptual adaptations to mosquitoes. Could we (or should we) change our perception of the mosquito from foe to friend? One Somerset resident saw this as something he might strive for: "I suppose if I was being consistent, I'd say I need to understand the sort of beings of mosquitoes and why they're there and cherish them, no doubt, but I haven't got to that stage yet! (Int. S1). Another Somerset resident adopted this approach, seeking to "learn to love the mosquito," as she says: 
One night I came out here and it was incredibly warm. It was a summer evening and I bumped into a group of people, only one of whom I knew at the time, a guy called Dave. He's a chef and a fisherman and you get absolutely plagued by mosquitos in the height of summer here and it can be pretty annoying. It was one of those nights, every single inch of the air was vibrating with insects. Dave is a fisherman and was in absolute raptures about this and was pointing out the swarms and he talked about the lifecycle of larvae and he talked about the way that this was the basic food stuff of fish, so the beginning of the whole food chain and how vital it was. It was fascinating and I thought there's no point in me carrying on being irritated with the mosquitos because it's not going to make them go away. So, if I can get a bit of Dave's love for them, perhaps it'll help. So, yeah, I try to learn to love the mosquito and I did find them significantly less troublesome after that

(Int. S5)

It seems that if people understand more about mosquitoes, their biology, and their place in nature, then their attitude towards these creatures may even shift from toleration to admiration. Indeed, a reserve manager in Bedford confessed to discovering a new admiration: "I find them fascinating" (Int. B13). Or to quote one of England's early mosquito foes, A. Moore Hogarth (1928), "we may have to modify the popular view of the mosquito as an entirely useless pest; indeed, as a subject for Nature study the mosquito, especially the male mosquito, is a thing of beauty" (pp. 30-31).

\section{Foe}

Our responses to mosquitoes are greatly shaped by the dominant historical and contemporary cultural representations we live amongst. The vast majority of practices that surround navigating mosquitoes are built on narratives of destruction, most particularly the need to obliterate this foe. Timothy Winegards's work Mosquito: A Human History of Our Deadliest Predator (2019) highlights all too readily the contemporary, populist view of these animals as a merciless villain to be annihilated. The mosquito's label as an enemy of humankind took root in the early 1900s, after Sir Ronald Ross revealed the link between mosquitoes and malaria. Yet, beyond imported mosquito-borne diseases such as malaria carried by soldiers returning from war, Britons have lived alongside mosquitoes without the risk of contracting their diseases for over a century. Still, some Somerset residents knew local stories of malaria, or "ague," which they explicitly linked to wetlands.

I've heard stories about mosquitoes. A local farmer tells me a story there used to be some sort of fever here centuries ago, that people used to get a fever and it was from the marshes, and he said it was probably caused by all the mosquitoes. So, they've been here for a long time. 


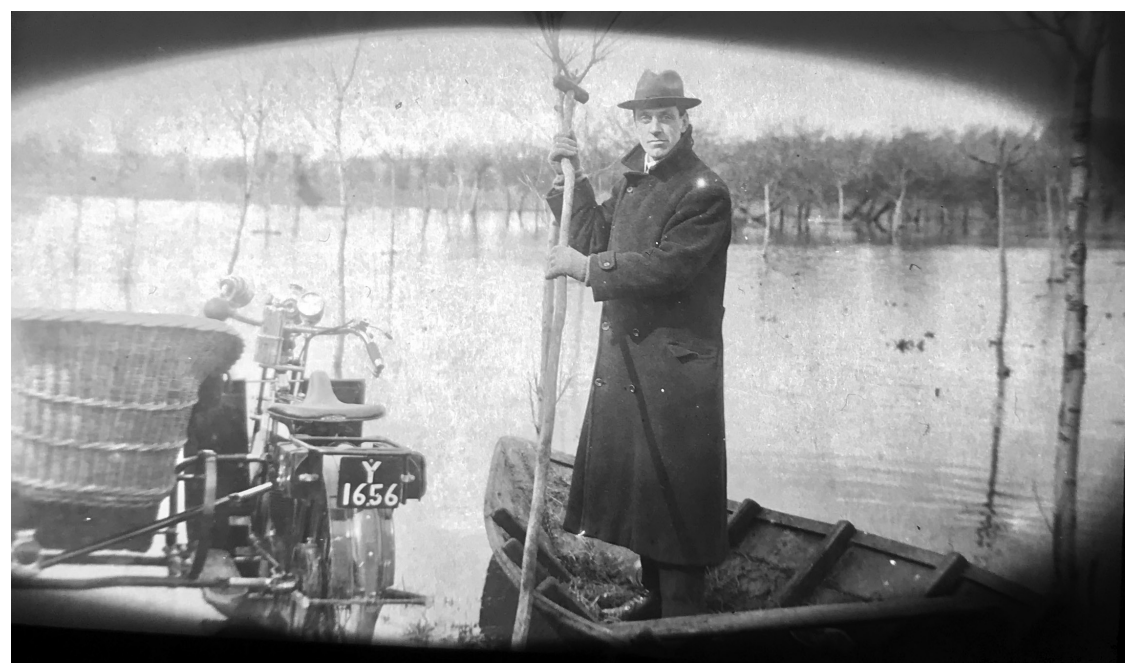

FIGURE 9.4 Dr Bracey, using a punt to visit patients in flooded moors of Somerset, circa 1913. Photograph courtesy of Hazel Hudson.

There were also rumours of a house in the Somerset moors, near Westhay Reserve, that used to treat ague- “It was an ague fever house. That's why the corner was always called Ague House Corner" (Int. S20)_along with a doctor who used to paddle across the marshes to treat those with the illness (Figure 9.4):

the local doctor would go out in his boat to them. If it was flooded, he had a flat bottomed turf boat and he would punt out to them and treat them. They lived upstairs if it was flooded. But I can't remember ... yeah, there were quite a few of them were suffering from this disease, whatever it was, that they called malaria.

(Int. S10)

Yet despite this knowledge of indigenous malaria in Britain, there is not much explicit anxiety linked to mosquitoes or wetlands. Instead, most fear of mosquitoes stems from news about recent epidemics, global travel and climate change. Headlines about the 2015-2016 Zika outbreak, particularly in South and North America, led to heightened mosquito awareness. Although Zika's responsible mosquito, Aedes Egypti, does not live in the UK's cooler climate, 314 cases were confirmed across the country in those travelling from affected regions (Public Health England 2019). It is therefore not surprising that some of the respondents did mention Zika, along with the more familiar malaria, as a possible future risks for the UK:

I think the concern around mosquitoes is if they were here in great numbers ... we saw this horrible disease in places such as, parts of South America, 
in Brazil, I can't remember the exact name, Zika, the Zika virus; if that was to spread to Europe and then into the UK, that could have devastating consequences really for us as humans.

(Int. B5)

And it is not just human diseases that are of concern when it comes to viewing mosquitoes as foe. For farmers, and other respondents grazing Exmoor ponies, they envisioned the primary diseases to be those confronting their domestic animals. Several references were made to Bluetongue, for example, a livestock disease vectored by midges. As a farmer near Alkborough explained,

I think as livestock farmers we're always worried about any insect, particularly if it's coming on a wind source from Europe ... obviously we keep having threats of bluetongue and other associated diseases-and so, yes, there's always a big worry with any specific insect

(Int. A9)

The connection between climate change and the northerly expansion of mosquitoborne diseases, and human agency as cause of and responder to climate change, was viewed by some respondents as additional justification for confronting the climate crisis: "With climate change we know things like Zika virus have been moving ... and it's why we should all take climate change seriously and we should do something about it" (Int. A12). The human role in spreading invasive mosquitoes (and the diseases that they carry) were also mentioned with reference to international transportation, and airports where "disease-ridden mosquitos would get a foothold" (Int. B2). The now heightened awareness of the role of travel in spreading disease and accelerating the COVID-19 pandemic will certainly heighten awareness, and indeed anxiety, of human agency in future mosquito threats.

\section{Searching for Mosquitopia in English wetlands}

So then, is it possible, at least in English wetlands, to learn to live side-by-side with mosquitoes without us killing them or them killing us? Or more specifically, might perceptions toward mosquitoes affect wetland management, restoration and creation? To provide an answer from an English perspective, realizing that wetlands are currently disease-free, we must declare that people living in or near these wetlands are already living in a form of Mosquitopia. Even if mosquitoes once transmitted malaria across the British Isles, with some of today's wetland users familiar with past "marsh fevers" and "ague," there are now many people who live, work or recreate in the breeding grounds of several mosquito speciescoexisting with the mosquito "foe" through reluctant toleration, indifference or even admiration. A species often portrayed as villain, or nuisance, has shown itself to be an appreciated strand in the web of life, supporting a food chain that sustains other, perhaps more charismatic species appreciated by people in wetland landscapes, some of which form the very reason people visit wetlands at all. 
Yet the yin of mosquitoes cannot ignore the yang of mosquitoes when developing plans to manage, restore and create wetlands. Mosquitoes here do cause severe nuisance in these wetlands even if they pose minor health threats, and so require human adaptations to fend off the wetland cohabiters. Whilst not at the forefront of people's concerns, the perceived possibility of mosquitoes carrying diseases to humans, or livestock, in the future, may modify the human-wetland-mosquito nexus. As Medlock and Vaux (2013) explain in the context of newly created wetlands (as in Alkborourgh), there is a "need for a case-by-case approach to design and management to mitigate mosquito or mosquito-borne disease issues now and in the future."

In 1928, A. Moore Hogarth wrote British Mosquitoes and How to Eliminate Them. If we want to avoid contributing to the "extinction narrative" but instead want to maintain a form of Mosquitopia, we need to prepare for a possible future in which mosquitoes are more prevalent, or even carrying diseases_although the actual risk in the UK is currently considered negligible. As one respondent from Bedford put it,

I think every animal somewhere or insect has a role to play, I'm perhaps not quite sure what their role in the ecosystem is, but I would assume that we'd probably do more damage by trying to eradicate them, as opposed to, by having them.

(Int. B5)

Through hearing the voices of those intimately connected to wetlands, we identified three key steps towards this goal. The first step, that of monitoring, is a case of "know thy enemy"; or as conservation volunteer in Somerset conveyed:

Monitoring it helps. It helps know what species there are. It helps to know what relative numbers there are so that if there are radical changes, and those radical changes are likely to impact on other organisms, then I think we need to know and make rational decisions about that.

(Int. S6)

The second step is to develop safe and effective management options, while recognizing that a balance must be sought. In particular, chemical methods of control may be viewed unfavourably, with more sympathetic management options (such as wetland design and management) being preferable, as an angler in Bedford, illustrated:

I am aware that some of the chemicals that have been used to destroy mosquitoes really can do other damage so I would hope that there's research going on so if that were to be the case, then we've got a solution in waiting. 
The third step is education and adaptation. Should English mosquitoes carry diseases in the future, a response might be developed by considering experiences with Lyme disease, which is managed through education and awareness of precautionary measures for avoiding and removing ticks. Indeed, many people already adapt to nuisance mosquitoes, and would extend these adaptations should the risk heighten:

I think you'd probably adapt to it because you'd find out what the risks were and what you could do to control the risks to yourself, and you would either dress or medicate accordingly, which is what we tend to do with ticks ... you would find a way to adapt to be able to carry on doing what you wanted to do.

(Int. A1)

Our respondents choose to live their lives embedded within these wetlands, having formed meaningful and intimate connections with these landscapes, developing senses of place and well-being, while confronting challenges that arise. Wetlands and people have formed strong relationships. Some of these places have always been wetlands; some were created over the last few thousand years during the transition from nomadic to settled farming; a few have been reclaimed more recently from coastal plains or constructed to replace other kinds of landscapes. Despite their differences and similarities, their histories recent and distant, wetlands are the setting for human-mosquito relationships. Humans and mosquitoes continue to coexist; both have, so far, resisted extinction unlike so many other creatures on this planet. The fact that mosquitoes still buzz demands a grudging respect for this most tenacious animal brethren. Communicating widely their role as pollinators, as fodder and biomass for a range of wetland creatures, whilst implementing sensitive management of their habitats where they are or may become bothersome, will play an essential part in developing a new, more intimate human-mosquito corps à corps.

\section{Acknowledgements and author contribution}

This research was carried out as part of WetlandLIFE project, funded and supported by the Natural Environment Research Council, the Arts and Humanities Research Council, the Economic and Social Research Council and the Department for Environment, Food and Rural Affairs under the Valuing Nature Programme (NERC grant reference number NE/NO13379/1).

Adriana Ford designed the study and collected and analyzed the data whilst working at the University of Greenwich. The chapter was written by Dr Adriana Ford and Dr Mary Gearey, with input from Dr Marcus Hall and Dr Dan Tamir. Dr Tim Acott managed the WetlandLIFE project as principal investigator, and contributed to the study design and provided the case study map. The ecological data for the case studies were provided by Dr Frances 
Hawkes, of the Natural Resources Institute, University of Greenwich. We thank all of the participants of the research for sharing their time and thoughts, and for the whole WetlandLIFE team for their ideas and support throughout the project.

\section{Interview key}

$\mathrm{A}=$ Alkborough Flats (and surrounding area); B = Bedford urban wetland parks (Bedford Priory Country Park and Millennium Country Park); S = Somerset Levels (Westhay Moor and Shapwick Heath, and surrounding landscape). The number is the chronological interview identifier (e.g. Int. A2 = second interview conducted in Alkborough).

\section{Data sharing and data accessibility}

Please contact WetlandLIFE principal investigator Dr Tim Acott at t.g.acott@ gre.ac.uk

\section{Bibliography}

Cohen, W.B. 1983. Malaria and French imperialism. The Journal of African History, 24(1), 23-36.

Daily Mail. 2019. Zika mosquitoes will come to the UK because of global warming risking a "large epidemic" of the incurable disease, MPs warn. Daily Mail, 3 April.

Dobson, M.J. 1989. History of Malaria in England. Journal of the Royal Society of Medicine Supplement, 17(Supplement 17), 82.

Dover District Council. 2020. Mosquitoes in the Dover District. https://www.dover.gov .uk/Environment/Environmental-Health/Pest-Control/Mosquitoes.aspx. Accessed 27 May 2020.

Ford, A. 2019a. Sport horse leisure and the phenomenology of interspecies embodiment. Leisure Studies, 38(3), 329-340.

Ford, A.E.S. 2019b. Mosquito and me - a narrative on mosquitoes in English wetlands in 2018. 11:30 min. https://www.youtube.com/watch? $\mathrm{v}=$ PPDPH0cqB $-\mathrm{s} \& \mathrm{t}=5 \mathrm{~s}$

Gearey, B.R., Charman, D.J. and Kent, M. 2000. Palaeoecological evidence for the prehistoric settlement of bodmin moor, Cornwall, Southwest England. Part I: The status of woodland and early human impacts. Journal of Archaeological Science, 27, 423-438.

Gearey, M., Church, A., and Ravenscroft, N. 2020. English Wetlands: Spaces of Nature, Culture and Imagination. London: Palgrave Macmillan.

Haraway, D. 2007. When Species Meet. Minneapolis: University of Minnesota Press. Haraway, D. 2016. Staying with the Trouble. Durham, NC: Duke University Press.

Hoffman, M.A. 2016. Malaria, Mosquitoes, and Maps: Practices and Articulations of Malaria Control in British India and WWII. Doctoral dissertation, University of California San Diego.

Hogarth, A.M. 1928. British Mosquitoes and How to Eliminate Them. London: Hutchinson $\&$ Co.

Howell, J. 2018. Malaria and Victorian Fictions of Empire. Cambridge: Cambridge University Press. 
Hudson, W. 2019. Horror as plague of killer mosquitos are headed to Britain as fears ramp up over insects. Express, 14 November.

Hume, C. 2008. Wetland Vision Technical Document: Overview and Reporting of Project Philosophy and Technical Approach. The Wetland Vision Partnership. https://www.lun evalleyfloodforum.org.uk/uploads/1/2/3/7/123753072/wetlandvision_tcm9-13295 7.pdf, accessed 05/05/21

Irvine, R. 2014. Deep time: An anthropological problem. Social Anthropology, 22(2), $157-172$.

Leather, S.R. 2017. 'Ecological Armageddon'-more evidence for the drastic decline in insect numbers. Annals of Applied Biology, 172(1), 1-3.

Malone, K. 2019. Co-mingling Kin: Exploring histories of uneasy human-animal relations as sites for ecological posthumanist pedagogies. In Animals in Environmental Education, T. Lloro-Bidart and V. Banschbach, eds. Cham: Palgrave Macmillan, 95-115.

Medlock, J.M and Vaux, A.G.C. 2013. Colonization of UK coastal realignment sites by mosquitoes: Implications for design, management, and public health. Journal of Vector Ecology, 38(1), 53-62.

Moore, Jason. 2015. Capitalism in the Web of Life. New York: Verso.

Public Health England. 2017. Guidance. Mosquito: Nationwide surveillance. Updated August 10. https://www.gov.uk/government/publications/mosquito-surveillance/ mosquito-nationwide-surveillance

Public Health England. 2019. Guidance. Zika virus: Epidemiology and cases diagnosed in the UK. February 27. https://www.gov.uk/government/publications/zika-virus -epidemiology-and-cases-diagnosed-in-the-uk/zika-virus-epidemiology-and-cases -diagnosed-in-the-uk

Ranger, S., Kenter, J.O., Bryce, R., Cumming, G., Dapling, T., Lawes, E. and Richardson, P.B. 2016. Forming shared values in conservation management: An interpretivedeliberative-democratic approach to including community voices. Ecosystem Services, 21, 344-357.

Sallares, Robert and Gomzi, Susan 2001. Biomolecular archaeology of Malaria. Ancient Biomolecules, 3(3), 195-213.

Sánchez-Bayo, F. and Wyckhuys, K.A.G. 2019. Worldwide decline of the entomofauna: A review of its drivers. Biological Conservation, 232, 8-27.

Schmidt, J.J. 2017. Water: Abundance, Scarcity, and Security in the Age of Humanity. New York: New York University Press.

Semenza, J.C. and Suk, J.E. 2018. Vector-borne diseases and climate change: A European perspective. FEMS Microbiology Letters, 365, fnx244.

Shamai, S. 1991. Sense of place: An empirical measurement. Geoforum, 22(3), 347-358.

Smart, C. 2011. Ways of knowing: Crossing species boundaries. Methodological Innovations Online, 6(3), 27-38.

Smith, M. 2013. Ecological community, the sense of the world, and senseless extinction. Environmental Humanities, 2(1), 21-41.

Solnit, R. 2010. Infinite City: A San Francisco Atlas. Berkeley: University of California Press.

Swain, M. 2012. Deadly mosquito found in the UK for first time since the 1940s. Daily Mirror, February 9.

Tsing, A.L. 2012. Unruly edges: Mushrooms as companion species. Environmental Humanities, 1, 141-54.

Vaux, A.G.C. and Medlock, J.M. 2015. Current status of invasive mosquito surveillance in the UK. Parasites \& Vectors, 8: 351. doi:10.1186/s13071-015-0936-9

Watts, S. 2006. Malaria and deaths in the English marshes. The Lancet, 368(9542), 1152. 
Wickson, F. 2010. Mosquitoes: Just how much biodiversity does humanity need? Nature, 466(7310), 1041-1041.

Winegard, T.C. 2019. The Mosquito: A Human History of Our Deadliest Predator. New York: Dutton.

Zahorik, P. and Jenison, R.L. 1998. Presence as being-in-the-world. Presence, 7(1), 78-89. 